\title{
PETRONIO EN LA BIBLIOTECA DE DES ESSEINTES: REFLEXIVIDAD Y DECADENCIA EN EL SATIRICÓN Y À REBOURS
}

\author{
MARIANO SVERDLOFF \\ Facultad de Filosofía y Letras de la Universidad de Buenos Aires - CONICET \\ marianojavs@yahoo.com.ar
}

\section{RESUMEN}

El objeto del presente artículo es hacer una comparación entre el Satiricón y À rebours (1884) de Joris-Karl Husymans. El Sat. define explícitamente las características generales de una sociedad y un lenguaje en declinación o inmorales, y traduce tales características a diversos niveles retóricos y constructivos de la obra. La novela À rebours de Huysmans, por su parte, describe una sociedad y un lenguaje decadentes y a partir de tal descripción postula una práctica y una teoría de la literatura. Estas escrituras paródicas e hiperalusivas son un comentario irónico y falto de integridad sobre la ironía y la falta de integridad del lenguaje.

PALABRAS CLAVE: Petronio; Huysmans; décadence; ironía; autorreflexividad.

\section{PETRONIUS IN DES ESSEINTES'S LIBRARY: SELF-REFLECTION AND DECADENCE IN THE SATYRICON AND À REBOURS}

\section{ABSTRACT}

The object of this paper is to compare the Satyricon and À Rebours (1884) by Joris Karl Husymans. The Sat. explicitly defines the general characteristic of a inmoral society and language, and translate such characteristics to the various rethorical levels of the text. Joris- Karl Huysmans uses the language of décadence to formulate a literature theory and an ars poetica of his own écriture artiste. These hiperalusive and parodic works are comentaries -both ironic and lacking of integrity- on the irony and lacking of integrity of the language.

KEYWORDS: Petronius; Huysmans; decadence; irony; self-reflection.

\section{INTRODUCCIÓN}

Como ha sido estudiado por la crítica (David 2001; David de Palacio 2005; De Longevialle 1999, inter al.), la revalorización de la literatura latina imperial y altomedieval que se da en a las últimas décadas del siglo XIX se funda en gran medida en la mitología de la décadence: la mentalidad decimonónica consideraba que obras como la Farsalia de Lucano, el Satiricón de Petronio o El rapto de Proserpina de Claudio Claudiano habrían sido el "síntoma" de la decadencia latina, de la misma forma que los poemas de Charles Baudelaire o Paul Verlaine serían el "síntoma" de la décadence del mundo burgués moderno. A partir de tal lógica (más histórica que literaria) se establece una supuesta equivalencia entre las obras "decadentes" de diversas épocas, sin que importen demasiado las adscripciones genéricas o las particularidades estilísticas. Así, en 
el capítulo III de À rebours de Joris-Karl Huysmans, se plantea un canon de la literatura latina centrado en la obra de Petronio, que incluye a autores tan disímiles como Apuleyo, Tertuliano o Rutilio Numatiano.

Ahora bien: la centralidad de Petronio en la biblioteca de Des Esseintes no responde, desde nuestro punto de vista, solamente a una provocativa reordenación del canon, sino también a una innegable afinidad estructural entre el Satiricón y À rebours, afinidad que se localiza, fundamentalmente, en el tipo de trabajo paródico y reflexivo que ambas obras hacen sobre los tópicos de la decadencia. El Sat. describe las características generales de una sociedad y un lenguaje en declinación o inmorales, y traduce tales rasgos a diversos niveles retóricos de la obra. Por su parte, como veremos en la segunda parte de este trabajo, À rebours describe una sociedad y un lenguaje decadentes y a partir de tal descripción postula una práctica y una teoría de la literatura. En ambos textos la descripción explícita que se hace del lenguaje de los tiempos decadentes o inmorales puede leerse como un comentario metatextual sobre la propia obra. Estamos antes comentarios irónicos y faltos de integridad sobre la ironía y la falta de integridad del lenguaje: a describir tal pliegue discursivo dedicaremos las siguientes páginas.

\section{LA REPRESENTACIÓN DE LA DESIDIAE PRAESENTIS EN EL SATIRICÓN}

El Sat. tematiza los lugares comunes del discurso sobre la inmoralidad romano. Así sucede, por ejemplo, con el tópico del triunfo de las bajas pasiones del cuerpo, estrechamente relacionado con el canibalismo y con la transgresión de las fronteras entre lo humano y lo animal. Otra característica de la desidiae praesentis ("pereza [del tiempo] presente" [Sat.88.1]) es la declinación de la retórica, causa y efecto del deterioro de las costumbres; se retoma así un difundido tópico en la oratoria latina, según el cual el lenguaje de las épocas inmorales es un lenguaje adulterado y deceptivo. Anexa a esta noción es la relación explícita que se establece entre el teatro y la declinación de los valores tradicionales, fundada en el vínculo que el imaginario romano planteaba entre el teatro y la licentia, entre la simulación -por definición afeminada- del hystrio, y la inmoralidad (Connolly 2007: 86).

Este triunfo de la teatralidad y el simulacro tiene como marco el desborde económico: se supone que la avaricia de las épocas inmorales genera un exceso en los flujos de bienes y moneda. Deudas, hipotecas, lujo suntuario, comercio, herencias fraudulentas, todas son formas de circulación que triunfan sobre las esferas de la producción, la moral y la virtud cívica. El Sat. pone en escena un desborde de las condiciones de intercambio que consideradas naturales por la mentalidad terrateniente y latifundista dominante en el modo de producción esclavista, entendido este en los términos de Hindress y Hirst (1979) y De Ste. Croix (1988). Y el cuerpo es, tal como ha estudiado la crítica de los últimos años, la metáfora privilegiada para expresar este desborde de los límites económicos 
“naturales" (Connolly 2007, Edwards, 2002, inter al.). La inmoralidad implica una recaída obscena en la corporalidad, que es a la vez una crisis del autocontrol y de la integridad, y una subversión de las jerarquías sociales. El Bellum Civile de Eumolpo es un excelente ejemplo de la estrecha relación que el discurso de la inmoralidad romana percibe entre desborde económico y pérdida de la integridad corporal. En las primeras líneas del poema se dice que los romanos, a pesar de haberse apoderado de todo el orbe, no estaban satisfechos: orbem iam totum victor Romanus habebat (...) nec satiatus erat ("Ya a todo el mundo dominaba el romano victorioso, pero no estaba saciado", Sat.119.BC.1-3). El origen de este desborde económico que llevará a la guerra civil reside en un descontrol de las pasiones y en el deseo de voluptuosidades inusuales (non vulgo nota placebant / gaudia, non usu plebeio trita voluptas, "placeres no conocidos por el vulgo gustaban, un deleite no frecuentado por la costumbre plebeya", Sat.119.BC.7-8). Este afán provoca la búsqueda desenfrenada de oro (Sat.119.BC.5-7), la afluencia hacia Roma de bienes exóticos traídos desde los confines más alejados del mundo (como seda de China y Numidia, Sat. 119.BC.11, tigres de África, Sat.119.BC.14-18), y la transgresión de las fronteras naturales entre géneros, pues se castra a los muchachitos púberes, según una costumbre persa, para servirse de ellos como compañeros sexuales (Sat.119.BC.20-24). Las (¿o los?) scorta gustan a todos los viri con sus refinamientos: (fractique enerui corpore gressus / et laxi crines et tot nova nomina vestis, / quaeque virum quaerunt, "y el paso quebrado del lánguido cuerpo y los cabellos sueltos y muchas nuevas vestimentas de nombres nuevos, y todo lo que excita al hombre", Sat.119.BC.25-28) y se asiste a una general corrupción de la vida pública (Sat.119.BC.39-53). El símbolo de esta comunidad inmoral es la citrea mensa (Sat.119.BC.28), hecha con un madera arrancada del África (Afris eruta terris, "arrancada de las tierras africanas", Sat.119.BC.27), que imita vilmente el oro (citrea mensa (...) ponitur ac maculis imitatur vilius aurum / quae sensum trahat, "se pone una mesa de cidro que con sus vetas imita vilmente al oro y traiciona a los sentidos", Sat.119. BC.28-30), y que es descripta como un male nobile lignum ("leño de malograda nobleza", Sat.119.BC.30), alrededor del cual se reúnen los greges servorum ("rebaños de esclavos", Sat.119.BC.28) y la turba sepulta mero ("turba sumergida en el vino", Sat.119.BC.31). La corrupción en Roma está provocada literalmente por el apetito desbocado (omniaque orbis/praemia correptis miles vagus esurit armis, " $\mathrm{y}$, tras apoderarse de las armas, el soldado errante tiene avidez de todos los botines del mundo", Sat.119.BC.31-2), por deseos nuevos y fuera de la naturaleza: Ingeniosa gula est ("es ingeniosa la gula", Sat.119. BC.33). El desborde de las pasiones implica una dimensión política: el furor, la ferro excita libido, (Sat.119.BC.60). De hecho, la propia sociedad romana es presentada como un cuerpo enfermo o herido: veluti tabes tacitis concepta medullis / intra membra furens curis latrantibus errat ("como una putrefacción, que formada en las calladas médulas [de los huesos], recorre delirando los miembros entre dolores que ladran", Sat.119.BC.54-5); ecce aliae 
clades et laesae vulnera pacis ("he aquí otras calamidades y heridas que acompañan a la paz quebrantada", Sat.119.BC.13).

La equivalencia metafórica entre Roma y un cuerpo despedazado es llevada hasta sus últimas consecuencias: la guerra civil es literalmente un acto de devoración. Dite en Sat.120.BC.96, dice que hace mucho que no rocía su boca con sangre (iam pridem nullo perfundimus ora cruore) y que Tisífone quiere bañar sus miembros sedientos (sitientis (...) artus, Sat.120.BC.97) en ese mismo cruor, del cual bebió la espada silana (Sullanus bibit ensis, Sat.120.BC.98). Estamos aquí, como explica Connors, ante una obsesión por la incorporación oral que afecta tanto a los individuos como al cuerpo político, y que nos acerca a los motivos de la animalización y el canibalismo. De allí que el apetito sin límites del miles nec satiatus, del miles que esurit, termine en el pedido de devoración por parte de la Fortuna a Tisífone: Tuque ingenti satiare ruina / pallida Tisiphone, concisaque vulnera mande: / ad Stygios manes laceratus ducitur orbis ("Y tu sáciate con la ingente destrucción, pálida Tisífone, y muerde las abiertas heridas: hacia los manes estigios se dirige el lacerado mundo", Sat.120.BC.119-21). Despedazamiento literal del orbis, a causa de la masticación o mordida (mandere), que, recuerda, tal como ha notado Connors (1998: 112-4) la devoración metafórica del universo por parte de Trimalción, quien convierte, mediante la representación culinaria de los signos del zodíaco, el propio universo en un cuerpo comestible (Sat.39.5-16).

La putrefacción de los membra de Roma es causada, pues, por el exceso de la circulación de mercancías: el imaginario romano interpreta las épocas de inmoralidad como un fallo general en las condiciones de intercambio que, se supone, deben existir entre las diversas jerarquías y posiciones sociales para que el "cuerpo social" se conserve. Y tal como veremos, el objeto por excelencia de ese intercambio social, a la vez que la mediación necesaria de cualquiera de ellos, el lenguaje, es concebido literalmente como un cuerpo deceptivo y desmembrado.

\section{EL LENGUAJE DE LA INMORALIDAD EN EL SATIRICÓN}

En la primera escena conservada del Sat., se acude a una extendida analogía de la oratoria latina: la performance del orador y el propio lenguaje son valorados a partir de la comparación con el corpus íntegro, impenetrable, y autocontrolado del vir (Connolly 2007). Claro que, al contrario que el vir, los declamatores de esta época inmoral carecen de autocontrol: num alio genere Furiarum declamatores inquietantur...? ("¿Acaso están agitados por otra clase de furias los declamadores...?", Sat.1.1); cf. también la frase de Agamenón: nihil mirum $\langle$ si $>$ in his exercitationibus doctores peccant, qui necesse habent cum insanientibus furere ("No es sorprendente si en estos ejercicios se equivocan los maestros, que necesitan enloquecer con los insensatos", Sat.3.2). El propio cuerpo del lenguaje es visto como un cuerpo debilitado: levibus enim atque inanibus sonis ludibria quaedam 
excitando, effecistis ut corpus orationis enervaretur et caderet ("al suscitar con sonidos ligeros y además vacíos una especie de bromas ilusorias, ustedes hicieron que el cuerpo del discurso se debilitara y sucumbiera", Sat.2.2) o hinchado, ampuloso (nunc et rerum tumore et sententiarum vanissimo strepitu hoc tantum proficiunt, "Ahora, tanto por la hinchazón de los temas como por la vanísima estridencia de la expresión", Sat.1.2; nótese que el campo semántico de tumor -oris incluye la hinchazón del cuerpo [OLD sv. tumor 1], el sentido figurado de estado inflamado de la mente [OLD sv. tumor 3] y el retórico de una dicción afectada [OLD sv. tumor 5]). Este discurso se opone a lo que debería ser la pudica oratio: grandis et, ut ita dicam, pudica oratio non est maculosa nec turgida, sed naturali pulchritudine exsurgit ("El grande, y por así decirlo, púdico discurso, no es colorido ni inflamado, sino que sobresale con natural belleza", Sat.2.6-7). Se trata de un cuerpo mal nutrido; ac ne carmen quidem sani coloris enituit, sed omnia quasi eodem cibo pasta non potuerunt usque ad senectutem canescere ("Y no brilló ciertamente poema [alguno] por su sano colorido, ni ninguna otra cosa, alimentada por la misma comida, pudo encanecer y llegar a la vejez", Sat.2.8-9).

Más aún, este lenguaje corrompido es comparado con el cuerpo consumible por excelencia, el de la comida, y ciertamente el de una comida demasiado condimentada: mellitos verborum globulos, et omnia dicta factaque quasi papavere et sesamo sparsa ("confites melosos de palabras, y todas las palabras y los hechos [representados en el discurso] como rociados con amapola y sésamo", Sat.1.3-2.1). El propio aprendizaje de esta retórica vana es una suerte de actividad culinaria: qui inter haec nutriuntur, non magis sapere possunt quam bene olere qui in culina habitant ("quienes se crían en medio de esto, no pueden juzgar con inteligencia, como tampoco huelen bien quienes viven en la cocina", Sat. 2.1-2). Como señala Gowers (1996), los cocineros son por definición seres sospechosos, en la medida en que pesa sobre ellos la sospecha de manipular las apariencias:

\footnotetext{
The cook, like the parasite, is a parodist. His arcane activities in the kitchen (to wich he give such spurious importance), his alteration of ingredients -by mincing, chopping, flavoring, and stuffing- mimic other forms of organization and alteration, particularty the activities of the comic author himself. (...) The cook, an entertainer of dubious worth, was an obvious parallel for the poet, and the comic poet in particular: cooks, with their ambitious claims for their untrustworthy art, deliver the same mixture of inane boasting and ironic self-deprecation. And the uncertain cultural status of gastronomy made it a good match for adramatic form [la comedia] that presented itself as only a botched and rehashed version of tragedy. (Gowers 1996: 78-79)
}

No es extraño, desde este punto vista, que la seducción del auditorio por parte del eloquentiae magister (Sat.3.4) se compare con el acto de cazar una presa para comerla: sic eloquentiae magister, nisi tanquam piscator eam imposuerit hamis escam, quam scierit appetituros esse pisciculos, sine spe praedae morabitur in scopulo ("así el maestro de eloquencia, a menos que como el pescador ponga en el anzuelo el cebo que sabe que apetecen los pececitos, esperará en la roca sin 
esperanza de cazar su presa", Sat.3.4-4.1). Aparecen aquí entrelazados varios núcleos fundamentales del Sat.: la devoración (que puede llevar al canibalismo, dado que el magister eloquentiae literalmente se come, a su auditorio, los pisciculos); el traspaso de la frontera entre lo humano y lo animal (el auditorio está conformado, precisamente, por pisciculos); la falsedad o la deceptividad del lenguaje y los intercambios económicos como generadores de esa inmoralidad (se debe recordar que la captación del público está motivada por esa misma venalidad que también demuestran los ficti adulatores cum cenas divitum captant, "los aduladores ficticios cuando intentan ser invitados a las cenas de los ricos", Sat.3.3).

Asimismo, el debilitamiento del cuerpo de este lenguaje está en directa relación con la falsedad en varios sentidos: por ejemplo, la propia del exceso del ornatus (levibus enim atque inanibus sonis ludibria quaedam excitando, effecistis ut corpus orationis enervaretur et caderet. Sat.2.2-3), o la de los clichés retóricos mencionados en el capítulo 1, que hace que los estudiantes de retórica, cuando pisan el foro se consideren in alium orbem terrarum delatos ("transportados a otra región de la tierra", Sat.1.3). Y tal como se verifica en el schedium Lucilianae humilitatis ("improvisación propia de la modestia de Lucilio", Sat.4.5) recitado por Agamenón, la falsedad se conecta explícitamente con la simulación del adulador y la inmoralidad propia del teatro en tanto espacio de licentia, que tiene como público una claque comprada:

\footnotetext{
nec curet alto regiam trucem vultu

cliensve cenas inpotentium captet,

nec perditis addictus obruat vino

mentis calorem; neve plausor in scenam

sedeat redemptus histrionis ad rictus.
}

\footnotetext{
Y que no se preocupe del fiero palacio de prestigiosa apariencia,

ni que como cliente busque las cenas de los desenfrenados,

ni que como secuaz de los perdidos sumerja en vino

el calor de su espíritu; ni que como aplaudidor pagado

se siente en el teatro para festejar la risa del histrión.

(Sat.5.4-8)
}

Otra falsificación es la resultante del desconocimiento o del manejo irresponsable de las fuentes que hacen los jóvenes aprendices de retórica o el doctor umbraticus que se menciona en Sat.2.4. (recordemos que el adjetivo umbraticus refiere a alguien que vive "en la sombra" dedicado a perseguir propósitos fútiles [Cf. OLD sv. umbraticus, - $a$, -um, donde se cita la expresión de Plinio en Ep.9.2.3: scholasticas... atque, ut ita dicam, umbraticas litteras]). Esta adulteración que lleva al reemplazo de un discurso virtuoso y fundado en las tradiciones, por uno falso que es como una parodia degradante de sus fuentes clásicas. Lo cual responde a una crisis de las costumbres en general y del 
sistema educativo en particular, producto de la ambitio, tal como se expone en todo el capítulo 4. Esta degradación del lenguaje, que se asocia, como hemos visto, con la puesta en cuestión de la fronteras del cuerpo (Sat.2.2), se origina en una transgresión de los límites entre lo externo e interno a nivel de las procedencias geográficas: esta retórica vacía o más bien "vaporosa" -esa sería la mejor traducción, a nuestro juicio, para ventosa-comparable con la enfermedad (veluti pestilenti quodam sidere), viene de Asia: nuper ventosa istaec et enormis loquacitas Athenas ex Asia commigravit animosque iuvenum ad magna surgentes veluti pestilenti quodam sidere adflavit, semelque corrupta eloquentiae regula ... stetit et obmutuit ("Recientemente, esa vaporosa y desmedida locuacidad pasó de Asia a Atenas y sopló como una suerte de astro pestilente sobre los espíritus de los jóvenes, [que estaban] dispuestos [sin embargo] para cosas importantes, y una vez alterada la norma de la elocuencia ... quedó inmóvil y enmudeció", Sat.2.78).

El lenguaje falso es, pues, literalmente pensado como un cuerpo mal (demasiado) alimentado, una comida demasiado elaborada, artificial. Tal como ha observado Victoria Rimmell, una de las principales obsesiones del Sat. es el cuestionamiento de las fronteras entre la exterioridad y la interioridad de los cuerpos (textuales) que son devorados o devoran a otros cuerpos (textuales). Y esta crisis de la incorporación se relaciona íntimamente, según hemos visto, con la falsedad y la venalidad: de allí que el público del teatro sea presa de los excesos en el schedium, lo cual anticipa la estrecha relación entre teatralidad y consunción (en ambos sentidos, el de consumo y el de agotamiento) que encontraremos en la cena de Trimalción.

Ahora bien: una vez que releemos la escena nos damos cuenta de que los enunciados de Agamenón y Encolpio están contaminados de los propios vicios que dicen condenar. En primer lugar, tal como reconoce Encolpio, su propio enunciado, en donde se censuran las declamaciones (Sat.2.3) es una declamación: non est passus Agamemnon me diutius declamare in porticu quam ipse in schola sudaverat ("No toleró Agamenón que yo declamara en el pórtico durante más tiempo del que él mismo había pasado sudando en el escuela", Sat.3.1). No podría ser de otra manera, dado que el lugar de este intercambio discursivo es una escuela de retórica (schola), bastante asistida, tal como parece sugerirse en 6.1 cuando se menciona una ingens scholasticorum turba "gran multitud de aprendices de declamadores". Es posible suponer que el discurso mismo de Agamenón es una estrategia de seducción para captar a Encolpio en tanto posible alumno. No olvidemos que el propio Agamenón asistirá en calidad de rétor adulador a la cena de Trimalción. Por otra parte, tal como dice Ascilto en el capítulo 10, la declamación de Encolpio tenía por objetivo hacerse invitar a cenar (Sat.10.2-3).

Asimismo, si la virtud predicada es fingida, estamos cerca de la falsedad inane de la retórica asianista (Sinclair 1984: 217). Recordemos además que el propio discurso de Agamenón es calificado de vitrea fracta et somniorum 
interpretamenta ("vidrios rotos e interpretaciones de sueños") por Ascilto en Sat.10.2. Y si aceptamos la hipótesis de Panoyatakis (1995), quien afirma que esta escena en particular y el Sat. en general presentan fuertes elementos intertextuales con el mimo y otros géneros teatrales bajos, nos encontramos con el hecho sorprendente de que esta denuncia del teatro y la adulación está armada como una escena (también teatral) de adulación para conseguir una invitación a cenar.

Del mismo modo, en el propio discurso de Agamenón encontramos elecciones léxicas que sugieren contradicciones con los mores que se declaman en su schedium. Así, observamos el uso del verbo ambire para refererirse al hecho de dedicarse a la oratoria entendida como ars severa (artis severae si quis ambit effectus / mentemque magnis applicat, prius mores / frugalitatis lege poliat exacta, "Si alguien ambiciona las realizaciones de un arte severa / y destina la mente a grandes cosas, que primero pula, / con la estricta ley de la frugalidad, sus costumbres", Sat.5.1-3); recordemos que ambire es una palabra connotada muy negativamente en el imaginario político romano, pues una de sus acepciones es la acción de adular con el objeto de obtener algún beneficio.

Por otra parte, la obsesión culinaria que anima a los aduladores se revela inopinadamente en dos momentos de los parlamentos de Agamenón, cuando el rétor utiliza el término sapor (palabra que alude a la sensación gustativa, $\mathrm{y}$, en el lenguaje de la retórica, al estilo de un discurso [Cf. OLD s.v. sapor -oris 1 y 2]) para referirse a dos discursos que, en principio, parecen totalmente alejados de ese universo degradado de la culina: el moralizante de Encolpio y el que sería el resultado de la práctica retórica recomendada por el propio Agamenón en su schedium (quoniam sermonem habes non publici saporis, "puesto que tienes un discurso de un sabor alejado de lo vulgar", Sat.3.1; hinc Romana manus circumflua, et modo Graio/ +exonerata+ sono mutet suffusa saporem, "que después fluya la tropa de modelos romanos, y que una vez aliviada del sonido griego, que [la voz del rétor] cambie, impregnada [por estos modelos], su sabor", Sat.5.15-16).

Asimismo, como explica Victoria Rimell, la poesía "luciliana" de Agamenón recurre a todo un campo semántico del desborde que se expresa particularmente en el empleo del verbo defundere, verbo que es usado para designar el pasaje de un determinado flujo entre el interior y el exterior de las fronteras corporales, y por cuyos cognados Petronio muestra una particular preferencia a lo largo de todo el Sat.:

The imaging of Roman literature as a free, liquid energy which once read, learnt and consumed is barely confinable within the human body, reverberates at significant junctures throughout the Satyricon. Agamemnon's poem at Sat. 5 is echoed particularly in the use of the verb fundere ('to pour') and its cognates: effundere ('to pour out'), perfundere ('to drench or anoint'), infundere ('to pour on/in'), and so on, words used regularly to express the sleppage or excretion of bodily fluids, the fall of rain and the flowing of rivers or streams, or the outpouring of words and sounds. (Rimell 2002: 26) 
Según la explicación de Agamenón, por tanto, el orador que ha incorporado toda una serie de modelos literarios, que ha hecho caso del consejo de beber con pecho feliz de la fuente meonia, esto es, homérica (Maeoniumque bibat felici pectore fontem, Sat.5.12) y que está "colmado" de la socrática grey (Socratico plenus grege, Sat.5.13), debe literalmente dar rienda suelta a su energía literaria. Se retoma la metáfora pindárica de la escritura como carrera de caballos y se recurre a expresiones que mezclan la fluidez líquida y la idea de liberación o expansión: mittat habenas / liber ("liberado suelte riendas", Sat.5.1314), det pagina cursum ("cobre movimiento la página", Sat.5.17), hinc Romana manus circumfluat ("que después fluya la tropa de modelos romanos", Sat.5.15), sic flumine largo / plenus Pierio defundes pectore verba ("así, colmado del abundante río Pierio [s.c. de las musas], verterás las palabras de tu pecho", Sat.5.21-2).

Esta liberación líquida de energías literarias nos permite una interpretación seguramente más apropiada que la del propio rétor Agamenón: aquella que hace Encolpio cuando entiende el discurso de Agamenón como una suerte de desborde y lo califica de dictorum aestu (Sat.6.1), algo así como "inflamación", "fiebre", "tumulto", "hervor", "tormenta" o -como traduce Eduardo Prieto- "marea de palabras" (cf. OLD s.v. aestus -us). Esta contradicción entre una declamada idea de autocontrol y elementos que la desmienten adelanta las inconsistencias que encontraremos también en la práctica discursiva de Eumolpo. Este poeta, que apela al decorum horaciano (refugiendum est ab omni verborum, ut ita dicam, vilitate et sumendae voces a plebe semotae, ut fiat "odi profanum vulgus et arceo", "se debe evitar toda vileza de las palabras, por así decir, y hay que elegir expresiones alejadas de la plebe, para que se cumpla [la máxima horaciana de] 'Odio al vulgo profano y me aparto'”, Sat. 118.4-5), se parece, inquietantemente, sin embargo, al mal poeta ridiculizado en el Ars Poetica de Horacio (Hor. Ars. 453-76).

Por otra parte la Troiae Halosis es calificada por Encolpio de morbus ("enfermedad", Sat.90.3), con lo cual estamos bastante cerca de los aegri somnia ("sueños de un enfermo", Hor. Ars.7) del Ars Poetica (Connors 1998: 144); la composición poética es comparada en Sat.115.1 con los gritos furiosos de una bestia (lo cual resignifica, por supuesto, las referencias a la inspiración como una pérdida del autocontrol que aparecen en el consejo de Eumolpo en el capítulo 118); finalmente, Eumolpo compara su propia práctica poética con un cibus ("alimento", Sat.90.6). La literatura se define como una serie de cuerpos heterogéneos: enfermedades, animales, alimentos. Lo cual es una excelente descripción, tal como veremos, de la dinámica textual del propio Sat., una obra que pone en acto aquellos usos del lenguaje que los censores de la inmoralidad romana repudian. 


\section{EL SATIRICÓN COMO UN CUERPO DESHECHO}

El Sat. puede interpretarse, para retomar las palabras con las que Eumolpo se refiere en Sat.118.5 a aquellos estilos que habría que evitar, como una serie de sententiae (...) extra corpus orationis expressae ("pensamientos expresados fuera del cuerpo del discurso"), que transgreden la invocación que el poeta hace del odi profanum vulgus et arceo (Sat.118.5). El Sat. es un texto que no contiene armoniosamente sus fuentes, que escapa a las máximas de autocontrol que son enunciadas explícitamente por Agamenón o Eumolpo, o que son invocadas implícitamente toda vez que se cita un género "oficial" y por tanto ya codificado. El Sat. más bien se parece a un fluir de modelos literarios, discursos populares y léxicos de procedencia diversa yuxtapuestos que destruyen la integridad del corpus orationis invocado en Sat.2.3 y Sat.118.5, pues incluye de modo heteroglósico diversos géneros (épica, tragedia, elegía, sátira menipea, mimo) para luego desbordarlos. Como sugiere Victoria Rimell, el propio texto se presenta como una satura, no en el sentido literario, sino en el sentido culinario del término, esto es, como un plato hecho de ingredientes de procedencias diversas (OLD s.v. satura 1). Un excelente ejemplo de esta dinámica textual que consiste en plantear una legalidad literaria o social para luego transgredirla, lo encontramos también en el empleo del intertexto épico. Pues si por un lado la elusiva voz autoral de Petronio parece ridiculizar el mal uso que Trimalción hace de sus fuentes épicas, por el otro la propia construcción del Sat. está plagada de "malas lecturas" de Virgilio y Homero, tal como se observa en el reemplazo de la furia de Poseidón por la de Príapo en el cap.139.

De este modo, la pérdida de integridad del cuerpo de los textos homérico y virgiliano duplica metatextualmente la pérdida de integridad de los cuerpos físicos: así sucede en la escena de Sat.132.8-11, donde Encolpio lamenta su impotencia, a través de una parodia obscena del Virgilio épico y bucólico (Slater 1990: 177-188 y Connors 1998: 30-32); o en Sat.59.2-7, donde a la desfiguración del intertexto homérico y trágico por parte de Trimalción le sigue el despedazamiento literal del cuerpo de un venado por un Áyax simulado, en una escena en la que se unen inextricablemente gastronomía, teatralidad, locura, deceptividad, y lectura incorrecta de las fuentes literarias:

ipse Trimalchio in pulvino consedit, et cum Homeristae Graecis versibus colloquerentur, ut insolenter solent, ille canora voce Latine legebat librum. mox silentio facto: 'scitis, inquit, quam fabulam agant? Diomedes et Ganymedes duo fratres fuerunt. horum soror erat Helena. Agamemnon illam rapuit et Dianae cervam subiecit. ita nunc Homeros dicit quemadmodum inter se pugnent Troiani et Tarentini. vicit scilicet et Iphigeniam, filiam suam, Achilli dedit uxorem. ob eam rem Aiax insanit, et statim argumentum explicabit.' haec ut dixit Trimalchio, clamorem Homeristae sustulerunt, interque familiam discurrentem vitulus in lance $d u<c e>$ naria elixus allatus est, et quidem galeatus. secutus est Aiax strictoque gladio, tanquam insaniret, $<$ vitulum $>$ concidit, ac modo versa modo supina gesticulatus mucrone frust $<r>$ a collegit mirantibusque [vitulum] partitus est. 


\begin{abstract}
“El mismo Trimalción se sentó en el almohadón, y mientras los homeristas dialogaban en versos griegos, insolentemente como suelen hacerlo, él leía un libro en latín con voz cantarina. Luego se hizo silencio. '¿Saben -dijo- qué obra representan? Diomedes y Ganimedes eran dos hermanos. La hermana de ellos era Helena. Agamenón la raptó y puso en su lugar a la cierva de Diana. Así lo cuenta Homero, por ese motivo combatieron troyanos y tarentinos. [Agamenón] venció, por supuesto, y le dio a Aquiles a su hija Ifigenia como esposa. Por ese motivo Áyax enloqueció, tal como ahora lo explicará el argumento'. Cuando Trimalción dijo esto, los homeristas elevaron un clamor, y entre los esclavos que corrían para abrir paso trajeron sobre una fuente de doscientas libras un venado cocido, que tenía asimismo puesto un yelmo. Lo seguía Áyax con la espada desenvainada, y como si estuviera loco, lo cortó en pedazos, y gesticulando para todos lados de modo engañoso pinchó los trozos con el arma, y los repartió entre los admirados [comensales]". (Sat.59.3-7)
\end{abstract}

Podemos decir, pues, que el propio Sat., con su hiperalusividad, su hipertextualidad y sus dificultades interpretativas, realiza esa deceptividad del lenguaje que caracteriza a los lenguajes de las épocas inmorales. Tal como dice Slater:

In a far deeper sense than is usually acknowledged, Encolpius's experience is our experience. The Satyricon consumes itself completely in the process of reading, leaving no hidden message behind, no secret structure suddenly revealed, only a reader simultaneously more capable of detecting fraudulent meaning and more hungry for a un elusive 'real'meaning. (...) The difficulties of the Satyricon's characters in reading and interpretation are ours. (Slater 1990: 250)

Lo cual se verifica, por ejemplo, con los juegos de palabras como ius cenae ("ley de la cena"/"salsa de la cena", Sat.36.1), embasicoeta ("copa para beber"/"afeminado", Sat.24.1-5), o carpe (como imperativo del verbo carpo / como vocativo del nombre propio del esclavo trinchador llamado Carpus, Sat.36.6-8), que sorprenden a Encolpio, pero que también sorprenden a un lector que sufre además las inconsistencias de ese narrador poco fiable, oscilante entre la ingenuidad y malicia, que es el propio Encolpio (Veyne 1964).

En suma: podemos interpretar al Sat. como un pliegue del lenguaje de la inmoralidad romana sobre sí mismo, ya que la obra muestra qué es una sociedad inmoral, explicita cómo es el lenguaje de esa sociedad, y traduce ese lenguaje a diversos niveles retóricos y formales. Tal como veremos, en $\grave{A}$ rebours encontraremos un procedimiento muy similar, dado que en la novela de Huysmans se teoriza qué es la decadencia, qué es un lenguaje decadente, y se pone a producir ese mismo lenguaje en el espacio de la obra.

\title{
5. La literatura como un CUerpo faisandé: Petronio en la biblioteca de DES ESSEINTES
}

Como se sabe, Huysmans pone en el centro de su biblioteca latina a la obra de Petronio. Este gesto, que en principio no parece demasiado original, dado que sigue la moda petroniana del fin-de-siècle, implica, como veremos más abajo, una especificidad que aleja a $\grave{A}$ rebours de las apropiaciones que se hicieron 
tanto del Sat. como de su autor en el siglo XIX, marcadas, en la mayoría de los casos, por una impronta fuertemente temática. Recordemos que la décadence decimonónica vio en el Satiricón un condensado de las transgresiones de la Roma decadente, un ejemplo de esa noción fantasmática de "orgía romana" que encontramos paradigmáticamente en un cuadro como Les romains de la décadence (1847) de Thomas Couture. Como explica Collignon (1905: 117 y ss.), a lo largo del siglo XIX, numerosos autores interpretaron la vida y la obra de Petronio en esa clave: Charles Nodier, en Questions de littérature légale. Du plagiat supone que el Sat. es la obra de un "libertino elegante" (1812: 89); Sainte-Beuve destaca en sus Portraits littéraires el inmoralismo de Petronio y la feliz ligereza de su tono (1862: 107-8); el erudito Jean-Jacques Ampère señala en su Histoire littéraire de la France avant le XIIe siècle la diferencia que existe entre la elegancia de la escritura del Sat. y lo bajo de sus temas (1839: 62). En el mismo sentido van las lecturas de Lucien-Anatole Prévost-Paradol, quien destaca en sus Essais de politique et de littérature la mundanidad de este "prince des élégants" (1863: 135); de Victor Hugo, quien cita a Trimalción en diversos pasajes de su obra del exilio para satirizar la figura de Napoleón III y de Gustave Flaubert, quien menciona al Sat. en diversas cartas y lo compara con Rabelais. Por su parte, Edmond de Goncourt encuentra parecidos entre la obra de Petronio y el Neveu de Rameau, y Ernest Renan compara el Sat. con los textos de Merimée ("Ce Mérimée sceptique, au ton froid et exquis, nous a laissé un roman d'une verve, de une finesse accomplies, en même temps que de une corruption raffinée, qui est le parfait miroir du temps du Néron", Renan 1873: 140). Baudelaire (quien además tenía proyectado traducir el Sat.) le dice a Jules Janin en una carta de 1865 que Trimalción es el mejor ejemplo de la felicidad en la vulgaridad y la bajeza (Baudelaire 1968: 652). Asimismo, diversas obras ficcionalizan al personaje Petronio o recrean episodios del Sat.: la Faustine (1864) de Louis Bouilhet retoma la cena de Trimalción, Jean Richepin imita a Petronio en algunos pasajes de sus Contes de la décadende romaine (1898), Eugène Verconsin reescribe el episodio de la matrona de Éfeso en su obra de teatro Matrone d'Éphèse (estrenada en 1869), Marcel Schwob reescribe escenas del banquete de Trimalción en Coeur double (1891) e incluye una biografía ficcional de Petronio en sus Vies imaginaries (1896). También Henryk Sienkiewicz (quien se inspiró en la biografía que Tácito hace de Titus Petronius Niger en Ann.16.18-19) presentó a Petronio como un refinado cortesano en Quo Vadis? El éxito de la obra (traducida al francés en 1896) dio lugar a una ola de novelas peplum similares, de las que se burlaría Rachilde acuñando el despectivo término quovadiser (David 2001: 23-5). En las últimas décadas del siglo XIX se asiste a una verdadera moda petroniana: en diversas obras se imagina a Petronio escribiendo el Sat. o recitando versos mientras muere, en una escena que interesa particularmente al fin-de-siècle porque combina agonía y escritura (David 2001: 466). El Sat. y su autor se convierten en un término de comparación para definir diversas manifestaciones literarias: así, Catulle Mendès compara a un personaje de la obra La Martyre de 
Richepin con una "page de Pétrone, traduite par Edgar Poë" (Le Journal, 19 de abril de 1898 [citado en David 2001: 462]). También aparecen en el siglo XIX gran cantidad de traducciones: las de Pierre Durand (1803), la de Charles Héguin de Guerle (1834, en la colección Panckoucke), la de Joseph Baillard (1842, en la colección Nisard), y la del escritor decadente Laurent Tailhade (1902), traducción esta que combina argot popular y latinismos, y en la que resuena, por tanto, la hibridez del texto petroniano.

Por su parte Huysmans, en el cap. III de À rebours, en el que se describe la biblioteca latina del dandy Des Esseintes, hace una lectura "al revés" de la historia de la literatura latina. A partir de esta inversión del canon, el clasicismo, sintetizado en la figura de Virgilio, es condenado en virtud de su artificialidad y falta de originalidad:

Entre otros el dulce Virgilio, ese que los celadores apodan el cisne de Mantua, sin duda porque no ha nacido en esa ciudad, le parecía, así como uno de los más terribles pedantes, uno de los más siniestros pesados que jamás haya producido la antigüedad; sus pastores pulcros y emperifollados que se descargan, por turno, sobre la cabeza, baldes llenos de versos sentenciosos y glaciales, su Orfeo que él compara con un ruiseñor en lágrimas, su Aristeo que lloriquea a propósito de unas abejas, su Eneas, ese personaje indeciso y esquivo que se pasea como una sombra china, con gestos de madera, tras la pantalla transparente mal sostenida y mal aceitada del poema, lo exasperaban. Hubiese aceptado las fastidiosas tonterías que intercambian estos personajes, tras bambalinas; hubiese aceptado los impúdicos préstamos tomados de Homero, Teócrito, Ennio y Lucrecio, el simple robo, según nos reveló Macrobio, del segundo canto de la Eneida, copiado casi palabra por palabra de un poema de Pisandro, en fin, toda la inenarrable vacuidad de ese amasijo de cantos; pero lo espantaba sobre todo la factura de esos hexámetros que sonaban a hojalata, a bidones vacíos, que alargaban la cantidad de las palabras tomadas por litro según la inamovible disposición de una prosodia pedante y seca, lo espantaba la contextura de esos versos ásperos y pretenciosos en su disposición oficial y su baja reverencia a la gramática, esos versos cortados, mecánicamente, por una impertubable cesura, taponados al final, siempre de la misma manera, por el choque de un dáctilo con un espondeo.

Tomada de la fragua perfeccionada por Catulo, esa métrica invariable, sin fantasía, impiadosa, atiborrada de palabras inútiles, de rellenos, de muletillas para ritornelos idénticos y previsibles; esa miseria del epíteto homérico retornando sin cesar, para no designar ni hacer ver nada, todo ese indigente vocabulario de matices insonoros y playos le resultaban un suplicio. (Huysmans 2005: 599-600 [Traducción nuestra])

El nuevo centro del canon es Petronio, de cuya obra se hace una atinada descripción, que mereció incluso la aprobación del erudito petroniano Albert Collignon (1905: 128-130):

El autor que él amaba verdaderamente y que lo hacía relegar para siempre de sus lecturas las resonantes destrezas de la Farsalia, era Petronio.

Era este un observador perspicaz, un analista delicado, un pintor maravilloso; tranquilamente, sin tomar posición, sin animosidad, describía la vida cotidiana de Roma, relataba en los pequeños y vivos capítulos del Satyricon las costumbres de su época. 
Anotando detalladamente los hechos, constatándolos en una forma definitiva, desarrollaba la existencia menuda del pueblo, sus episodios, sus bestialidades, sus ardores.

Aquí, el inspector de hostales que viene a preguntar el nombre de los viajeros que recién han llegado; allí, los lupanares donde la gente da vueltas alrededor de mujeres desnudas, paradas en medio de letreros, mientras que por las puertas mal cerradas de las habitaciones se entrevén parejas retozando; en todas partes, entonces, tanto a través de villas de un lujo insolente y una demencia de riqueza y fasto, como de los pobres albergues con camas de correa deshechas, llenas de chinches, que se suceden en el libro, se agita la sociedad del momento: corrompidos rateros, como Ascylto y Eumolpo, en busca de un golpe de suerte; viejos íncubos de ropas levantadas, de mejillas estucadas con blanco plomizo y rojo de acacia; mancebos de dieciséis años, rollizos y rizados; mujeres presas de ataques de histeria; cazafortunas ofreciendo sus hijos e hijas a los excesos de los testadores; todos corren a lo largo de las páginas, discuten en las calles, se acarician en los baños, se golpean violentamente como en una pantomima.

$\mathrm{Y}$ todo relatado en un estilo de un verdor extraordinario, de un color preciso, un estilo sacado de todos los dialectos, que tomaba expresiones de todas las lenguas que llegaban hasta Roma, un estilo que, haciendo retroceder todos los límites, todos los obstáculos del así llamado Gran Siglo, hacía hablar a cada uno su idioma: a los libertos sin educación, el latín populachero, el argot de la calle; a los extranjeros su jerga bárbara, mestizada con africano, sirio y griego; a los pedantes imbéciles, como el Agamenón del libro, una retórica de palabras postizas. Estas gentes son dibujadas de un trazo, repantigadas alrededor de una mesa, cambiando insípidas conversaciones de borracho, desgranando máximas seniles y refranes ineptos con las jetas hinchadas vueltas hacia Trimalción, quien se limpia los dientes con palillos, ofrece orinales a los invitados, les habla de la salud de sus entrañas y expele ventosidades, invitando a sus comensales a ponerse cómodos.

Esta novela realista, este trozo cortado de lo más intenso de la vida romana, sin preocupación (más allá de lo que pueda decirse sobre lo relatado) de reforma o de sátira, sin necesidad de un fin determinado o de moral; esta historia, sin intriga, sin acción, que pone en escena las aventuras de las presas de Sodoma; que analiza con una plácida fineza las alegrías y los dolores de esos amores y de estas parejas; que cepilla, con una lengua de una espléndida orfebrería, sin que el autor se muestre una sola vez, sin que se permita ningún comentario, sin que apruebe o censure los actos o los pensamientos de sus personajes, los vicios de una civilización decrépita, de un imperio que se resquebraja, esta obra lo cautivaba a Des Esseintes, y entreveía en el refinamiento del estilo, en la acuidad de la observación, en la firmeza del método, singulares aproximaciones, curiosas analogías con las pocas novelas modernas francesas que toleraba. (Huysmans 2005: 601602)

Ahora bien, esta lectura del Sat. es índice de una profunda afinidad estructural entre ambas obras, que se verifica al nivel del trabajo reflexivo sobre el discurso de la decadencia. En la novela de Huysmans nos encontramos con un pliegue similar al que hemos descripto en el Sat., y esto la distingue significativamente de las otras apropiaciones que hemos reseñado, de corte más bien temático. Acudiendo a tópicos como la descomposición, la falsificación y la desintegración corporal, À rebours describe una sociedad decadente, en la que el triunfo de los intercambios económicos ha adulterado los valores tradicionales; y tal como ocurre en el Sat., estos mismos tópicos sirven para plantear una teoría del lenguaje literario. En À rebours la lengua misma es planteada como un 
faisandage (Huysmans 2005: 605), y a partir de esta metáfora Huysmans enuncia una suerte de arte poética de su écriture artiste (Cressot 1938) que también permitirá reordenar, en los capítulos XII y XIV de la novela, el canon de la literatura francesa decimonónica. En la biblioteca latina de Des Esseintes volvemos a encontrar para definir al lenguaje y la literatura tópicos que ya habíamos advertido en la obra de Petronio: el artificio, la adulteración, la heteroglosia entendida como descomposición, la relación entre falta de integridad del lenguaje y fronteras geográficas, la lengua misma como un cuerpo orgánico que se pudre, se desintegra o puede ser devorado. Así se advierte, por ejemplo, en los párrafos dedicados a Cicerón y César, en la reseña de la obra de Apuleyo, o bien en la descripción de la literatura latina contemporánea a la caída del Imperio Romano de Occidente:

En prosa, la lengua verbosa, las metáforas redundantes, las digresiones incomprensibles del Cícharo [Cicerón], le disgustaban por igual; la jactancia de sus apóstrofes, el movimiento de sus repetidas fórmulas patrióticas, el énfasis de sus arengas, la masa pesada de su estilo, carnoso, cebado, pero grasoso y sin médulas ni huesos, las insoportables escorias de sus largo adverbios encabezando la frase, las inalterables fórmulas de sus adiposos períodos mal conectados entre sí por el hilo de las conjunciones, en fin, su cansador hábito de la tautología, no lo seducían de ninguna manera; y tampoco más que Cicerón lo entusiasmaba César, reputado por su laconismo, pues se mostraba entonces el exceso contrario, una autoritaria aridez de pedo-seco, una esterilidad de memorándum, una constipación increíble, injustificada. (Huysmans 2005: 600)

Este Africano [Apuleyo] lo regocijaba; en sus Metamorfosis la lengua latina llegaba a un punto culminante, acarreando limo, aguas variadas y precipitadas de todas las provincias, que se mezclaban, se confundían en una coloración extraña, exótica, casi nueva; los manierismos, los detalles novedosos de la sociedad latina encontraban un molde en los neologismos creados por la necesidad de la conversación, en un rincón romano del África; además su jovialidad de hombre evidentemente grueso, su exuberancia meridional divertía a Des Esseintes. Aparecía así como un salaz y alegre compadre al lado de los apologistas cristianos que vivían en el mismo siglo, al lado del soporífero Minucio Félix, un pseudo-clásico, que colaba en su Octavius los oleosos emulsivos todavía espesos de Cicerón, y por cierto al lado de Tertuliano, que él conservaba quizá más por su edición de Aldo que por la obra misma. (Huysmans 2005: 603)

El interés que Des Esseintes tenía hacia la lengua latina no se debilitaba, ahora que completamente podrida, ella colgaba, perdiendo sus miembros, goteando pus, conservando todavía, en toda la extensión de su cuerpo, algunas partes firmes que los cristianos desprendían para marinar en la salmuera de su nueva lengua. (Huysmans 2005: 609)

Digamos asimismo que el propio lenguaje de $\grave{A}$ rebours, que se sirve de procedimientos tales como el pastiche, la cita desplazada o la parodia, recuerda a esa proceder híbrido y deceptivo que, se supone, tienen los discursos de las épocas decadentes; un excelente ejemplo es el propio texto del capítulo III que, tal como ha demostrado la crítica, está hecho con citas, a menudo provocativamente invertidas o retocadas, de manuales de literatura del siglo XIX 
(Gomez y Van de Ven 1996). Esta escritura hiperalusiva, que multiplica las referencias literarias y culturales de modo paródico y desplazado, se constituye, por tanto, como un comentario irónico y falto de integridad sobre la ironía y la falta de integridad del lenguaje; y esta autorreflexión lleva a una indeterminación del sentido comparable a la deliberada deceptividad que encontramos en el texto petroniano.

\section{CONCLUSIONES: REFLEXIVIDAD, NOVELA Y DECADENCIA}

En $\grave{A}$ rebours de Huysmans encontramos un pliegue similar al que describimos en Petronio, dado que en esta obra la supuesta descomposición de las épocas decadentes se traduce a diversos niveles constructivos y sirve para enunciar una teoría de la literatura. ¿Pero a qué se debe esta semejanza? La explicación debe buscarse, desde nuestro punto de vista, en la ruptura de Huysmans con el naturalismo. Cuando Huysmans se distancia de Zola, se inclina por una idea de la novela como mezcla de géneros, que es muy similar a la que proponía Friedrich Schlegel en la "Carta sobre la novela" incluida en su "Conversación sobre la poesía" (1800), uno de los textos centrales para entender la relación entre autorreflexividad y novela que planteaba el romanticismo de Iena. Y esta idea, que se apoya, a su vez, en toda una línea de interpretación romántica que revaloriza el carácter híbrido de la literatura latina frente a la supuesta pureza de la griega, será fundamental, como ha demostrado Micéala Symington (2006), para toda la crítica de arte simbolista y decadente. De allí que en la descripción que se hace en $\grave{A}$ rebours del Sat. advirtamos junto al modelo naturalista ("Esta novela realista, este trozo cortado de lo más intenso de la vida romana") el paradigma que podríamos llamar schlegeliano, que se centra sobre todo en el aspecto polifónico de la obra de Petronio ("un estilo que, haciendo retroceder todos los límites, todos los obstáculos del así llamado Gran Siglo, hacía hablar a cada uno su idioma: a los libertos sin educación, el latín populachero, el argot de la calle; a los extranjeros su jerga bárbara, mestizada con africano, sirio y griego; a los pedantes imbéciles, como el Agamenón del libro, una retórica de palabras postizas").

Ahora bien, al revalorizar este modelo polifónico de novela, Huysmans se aproxima a esa mezcla de géneros que ya había practicado en su propia crítica de arte, donde la reflexión se superpone con la narración, la valoración crítica y le teoría. En Huysmans, novela y autoreflexividad crítica tienden a coincidir: la escritura decadente incluye a su propia teorización. Tal "autorreflexión" no implica una descripción exterior, sino más bien un diálogo, a través del cual el propio lenguaje participa de aquello sobre lo que reflexiona. Ya no se trata de una observación "objetiva", como la que propone Zola en Le roman expérimental (1881), sino de una parodia, donde parodiar significa, también, incorporar, absorber aquel discurso que se cita. $Y$ en este caso, lo que se incorpora a través de la parodia es la desintegración del lenguaje propia de la décadence. Estamos 
ante una "ironía de ironías", para retomar la fórmula que utiliza Friedrich Schlegel en "Sobre la incomprensibilidad" (1800) que genera graves problemas interpretativos, porque se habla sobre la deceptividad y la falta de integridad de un modo también deceptivo y falto de integridad. Se advierte la afinidad que existe entre la definición que encontramos en el Sat. de la literatura como una serie de sententiae (...) extra corpus orationis expressae y la metáfora del cuerpo podrido (faisandé) a la que recurre Huysmans para referirse a la tradición literaria: ambas son formas de mentar la desintegración del lenguaje. En este sentido, la centralidad del Sat. en la biblioteca de Des Esseintes va más allá de la circunstancial adhesión a la moda petroniana de las últimas décadas del siglo XIX, y es índice de una homología estructural entre ambos discursos sobre la decadencia.

\section{BIBLIOGRAFÍA}

AA.VV. (2009), Petronius: A Handbook, Repath, I. (ed.), Chichester/Malden, MA, WileyBlackwell.

AMPÈRE, J.-J. (1839), Histoire littéraire de la France avant le XIIe siècle, Paris, Hachette.

BAudelaire, CH. (1968), Oeuvres Complètes, Paris, Éditions du Seuil.

BOIRE, J. (1991), Huysmans: Le Diable, le célibataire et Dieu, Paris, Bernard Grasset.

CALlU, J.P. (1997), “Les Romains de la Décadence: regards du XIXe siècle français (1809-1874)", Comptes-rendus des séances de l'Académie des Inscriptions et BellesLettres, 141e année 4, 1143-1156. [Consulta: 01/11/2012]. Disponible en: $<$ http://www.persee.fr/web/revues/home/prescript/article/crai_00650536_1997_num_141_4_15810> doi: dx.doi.org/10.3406/crai.1997.15810

CEARD, J. (1978), “Des Esseintes et la décadence latine, Huysmans lecteur de Dom Rivet, de Chateaubriand et d'Ozanam", en Studi francesi 65-66, 298-310.

ChevallieR, R., (2002), “La bibliothèque de Des Esseintes ou le latin 'décadent': une question toujours d'actualité", Latomus 61.1, pp.163-177.

Collignon, A. (1905), Pétrone en France, Paris, A. Fontemoing.

Connolly, J. (2007), "Virile Tongues: Rhetoric and Masculinity", en A Companion to Roman Rethoric, Dominik, W., y Hall, J. (eds.), Mardlen-Oxford-Carlton, Blackwell, 83-97.

CONTE G. (1996), The Hidden Author. An Interpretation of Petronius'"Satyricon", BerkeleyLos Angeles-London, California U P.

CRessot, M. (1938), La phrase et le vocabulaire de J.-K. Huysmans, Paris, Droz.

DAvid, M.-F. (2001), Antiquité latine et Décadence, Paris, Honoré Champion.

DAVID DE PALACIO, M.-F. (2005), Réviviscences romaines, La latinité au miroir de l'esprit fin-de-siècle, Bruxelles, Peter Lang.

De LONGeVialle, A.(1999), Le roman de Rome: antiquité et decadence dans la littérature française de la fin du dix-neuvième siècle, Tesis inédita en microfilm en el Atelier National de Reproduction des Thèses.

DE STE. CROIX, G.E.M. (1988), La lucha de clases en el mundo griego antiguo, Barcelona, Crítica.

DonAto, E. (2004), Beyond the Paradox of the Nostalgic Modernist. Temporality in the Works of J.-K. Huysmans, New York, Peter Lang. 
EDWARDS, C. (2002), The politics of immorality in Ancient Rome, Oxford U P.

FEDELI, P. (1991), "Satira e realtà in mutamento: un mondo alla rovescia petroniano", en Continuità e trasformazioni fra republica e principato, M. Pani (ed.), Bari, École française de Rome 1991, 225-232.

FitzGERALD, W. (2000), Slavery and the Roman Literary Imagination, Cambridge, Cambridge U P.

GenetTe, G. (1989), Palimpsestos: la literatura en segundo grado, Madrid, Taurus.

GoMeZ, C. y VAN DE VEN, M. (1996), “La bibliothèque latine de Des Esseintes comme métaphore de l'esthétique décadente", en Les Décadents à l'école des Alexandrins, colloque international des 30 nov.-1er déc. 1996 à l'université de Valenciennes, études rassemblées et présentées par Perrine Galand-Hallyn, P. Galland-Hallyn (ed.), Presses Universitaires de Valenciennes, 157-170.

GOWERS, E. (1996), The loaded table: representations of food in Roman literature, Oxford, Oxford U P.

HuYSMANS, J.-K. (1997), À rebours (edición de Marc Fumaroli), Paris, Gallimard.

HUYSMANS, J.-K. (2005), Romans I (edición de Pierre Brunel), Paris, Robert Laffont.

HuYSMANS, J.-K. (s/d), reseña a Gamiani de Musset.

MAHIEU, R. (1996), Les Décadents à l'école des Alexandrins, colloque international des 30 nov.-1er déc. 1996 à l'université de Valenciennes, études rassemblées et présentées par Perrine Galand-Hallyn, en P. Galland-Hallyn, (ed.), Presses Universitaires de Valenciennes, 107-121.

MüLler, K. (2003), Petronii Arbitri Satyricon reliquiae. Edidit Konrad Müller. Editio iterata correctior editionis quartae (MCMXCV), Monachii et Lipsiae (Munich y Leipzig), K.G. Saur.

NODIER, CH. (1812), Questions de littérature légale. Du plagiat, Paris, Crapelet.

PANAYOTAKIS, C. (1995), Theatrum Arbitri: Theatrical Elements in the Satyrica of Petronius, Leiden, E.J. Brill.

PRIETO, E. (2002), Petronio. Satiricón, Buenos Aires, EUDEBA.

RENAN, E. (1873), L'Antechrist, Paris, M. Lévy frères.

Rimmel, V. (2003), Petronius and the Anatomy of Fiction, Cambridge, Cambridge University Press.

Rud, N. (1986), Horace. Epistles Book II and Ars Poetica, Cambridge, Cambridge U P.

SAINTE-BeUve, CH.A. (1862), Portraits littéraires III, Paris, Garnier.

SINCLAIR, B.W.(1984), "Encolpius And Asianism (Satyricon 2.7.)”, en Classical texts and their traditions. Studies in honor of C.R. Trahman, Bright, D.F., y Ramage, E.S., Chico, California, 231-237.

SCHLEGEL, F. (2005), Conversación sobre la poesía, Buenos Aires, Biblos.

SCHLEGEL, F. (1983), Obras selectas, Madrid, Fundación Universitaria Española.

Slater, N.W. (1990), Reading Petronius, Baltimore and London, The Johns Hopkins U P.

Sullivan, J.P. (1985), Literature and Politics in the Age of Nero, Ithaca-London, Cornell University Press.

SYMINGTON, M. (2006), Écrire le tableau: L'approche poétique de la critique d'art à l'époque symboliste, Bruxelles, Presses Interuniversitaires Européennes-Peter Lang.

TAILHADE, L. (1902), Pétrone. Le Satyricon. Traduction nouvelle par Laurent Tailhade. Préface de Jacques de Boisjoslin, Paris, Fasquelle. 
Thorel-Cailleteau, S. (2000), "Décadence - inanité sonore", en Dieu, la chair et les livres. Une aprroche de la décadence (Thorel-Cailleteau, Sylvie comp.), S. ThorelCailleteau, S. (ed.), Paris, Honoré Champion, 11-27.

VEYNE, P. (1964), “Le 'je' dans le Satyricon”, REL 42, 301-324.

VEYNE, P. (1961), “Vie de Trimalcion”, AESC Vol.16 N. 2, 213-247.

VON ALBRECH, M. (1997), A history of roman literature, From Livius Andronicus to Boethius, with special regard to its influence on world literature, Leiden, New York, Koln, E.J. Brill.

Zeitlin, F. (1971), "Petronius as Paradox: Anarchy and Artistic Integrity," Transactions and Proceedings of the American Philological Association, Vol. 102, 631-84. 